\title{
Two Suns? The State of Amazon? Bezonomics, market control and the algorithmic state.
}

Why do people vote? What do they need?

The book Bezonomics by Brian Dumaine has got me back to thinking about such questions. People might vote for better quality of life and Amazon, the company founded by Bezos might now be supplying this according to what people like. Amazon offers options to prefer across their lives.

Another book I had read earlier, The Warehouse by Rob Hart had started me off on the Bezos trail, so to speak. I now want to look at what kind of an entity Amazon is. Is it an entity that now has a force, a scale, an ethic and a set of borders that speaks of a state-like situation wherein people rely and trust Amazon to fulfil their needs?

Speaking of starting, a lifetime ago I did a doctorate about the situation of Maori in New Zealand in the nineteenth century. Based on that thesis I wrote an article for the Journal of the Polynesian Society in 1983 on the emergence of an early state situation in Maori society in the nineteenth century.

Amazon in 2020 seems in another time and space but here goes...

Professor Peter Cleave is a Research Associate in the Faculty of Health and Environmental Sciences (AUT University), a Visiting Fellow in Te Ara

Poutama (AUT University), a Member of Common Room, Wolfson College (Oxford University), and a Broadcaster in Te Reo Maori at Kia Ora FM. 
As with Amazon today the situation with the iwi in New Zealand in the mid-nineteenth century was to do with scale. Tribes were gathering under a mantle that being the Kingitanga or King Movement. My thesis was that this combination of iwi, of tribes, had been developing and becoming pan tribal in certain respects before contact and after 1840 .

One driver of this line of thought has been for me the idea of a communications nexus. Amazon offers such and a shared kawa or process of communication on marae where information is presented and debated offers something similar in Maori society.

Contact with outsiders to Aotearoa-New Zealand was a major multiplier for the King Movement. With several challenges including imported disease and sickness as well as war and the confiscation of their lands and a foreign culture pan-tribal strengthening continued apace after contact. Nativist Christianity and the emergence of prophets sharpened the mix. Ideology tightened; in speechmaking throughout the district of the Kingitanga the first mention is of God and the next of the King.

Amazon was growing before Covid but now assumes greater significance. Covid has acted as a multiplier for Amazon with the home becoming the working as well as the living space for many. Providing delivery to the door quickly as well as Alexa, the voice of the robot friend, cloud services and other things that were now competitive for the person at home, Amazon became a way to (almost) instantly gratify, a way for the family to cope at close quarters with a hostile environment outside in the form of a pandemic. Have there been image changes, a tightening of Amazon identity since Covid?

Given the scale of the decimation of Maori society by sickness in the nineteenth century the analogy or comparison of contact with coronavirus is not unfair. 
Are such responses best seen as defensive mechanisms or locks into the long haul?

What are their anchors? Is the King Movement anchored to the New Zealand state? One thinks of Governor Grey's question to the Maori King, 'Are there two suns in the sky?' And one thinks of an apparent animosity on the part of the President, Donald Trump towards Geoff Bezos of Amazon which is discussed below. Is Amazon anchored to the USA where it began? Do either need anchors?

In any event this is how my enquiry started with a reflection back on my D.Phil and with these sorts of questions. Now I want to look at Amazon with regard to recent literature taking five or six works into consideration these being Lina Khan's writing on Amazon and antitrust legislation, Steven Berry's work on hubs, Geoffrey West's book Scale as well as the work by Dumaine and Hart mentioned above along with references to a recent book by Ronan Farrow and a consideration of Gaby Wood's Living Dolls.

Dumaine's work is critical. His book Bezonomics is the primer in a study of Amazon charting the rise of Bezos, the use of algorithms and 'the Amazon flywheel' in a clear and effective manner and making several critical insights as far as this presentation is concerned including the reference to antitrust legislation of 1905.

Hart's book The Warehouse which is not an academic thesis but a futuristic view of Amazon - the company not being mentioned by name in the book- is prescient in terms of the multiplier effect that the pandemic has had on Amazon. There are several insights in The Warehouse that might inform this presentation but the vision, what seems to me to be an accurate one, of an America or a world becoming more dependent on Amazon-like hubs is in keeping with its 2019 publication date. 
West's book Scale applies in various ways to the work of Hart and Dumont. While West thinks that the city is more resilient than the company the scale and longevity of Amazon might both be of consideration to him. A particularly important consideration might be that cities are controlled by governments as a matter of space. Cities exist within countries. When the hub is in the sky, so to speak, in the cloud, when the arterial routes of road and sea are replaced by drone transport in the sky that connection weakens. And if the hubs are in outer space, bearing in mind the space activities of Bezos, Musk and others then we have a scale of things extraterrestrial and, potentially at least, a new form of state- like activity along with new stars and suns to consider.

When it comes to centralisation, a key part of state development, the development of the incipient state, if you like, the way Amazon centralises becomes critical. The question of which city Amazon chooses as its centre becomes a significant issue. More than that though there is the question as to whether Amazon needs to be based anywhere in the USA or anywhere else in particular for that matter. Given the matter of the cloud and given the exploration of space we could be talking about cyberspace or outer space as much as terrestrial space when it comes to choosing a centre of operations.

Khan's Yale Law School Journal article about Amazon and antitrust legislation in the USA is important with its reference to the Chicago School and the emphasis on the consumer making Amazon hard to reach by people wanting to break it up. I note Dumaine's attention to the emphasis that Bezos has on customer satisfaction, this being the key driver of the Amazon flywheel. 
As the New York Times says of Khan:

Her argument went against a consensus in antitrust circles that dates back to the 1970s - the moment when regulation was redefined to focus on consumer welfare, which is to say price. Since Amazon is renowned for its cut-rate deals, it would seem safe from federal interventions. Khan disagreed. Over 93 heavily footnoted pages, she presented the case that the company should not get a pass on anticompetitive behavior just because it makes customers happy. Once-robust monopoly laws have been marginalized, Ms. Khan wrote, and consequently Amazon is amassing structural power that lets it exert increasing control over many parts of the economy.

Amazon has so much data on so many customers, it is so willing to forgo profits, it is so aggressive and has so many advantages from its shipping and warehouse infrastructure that it exerts an influence much broader than its market share. It resembles the all-powerful railroads of the Progressive Era, Ms. Khan wrote: "The thousands of retailers and independent businesses that must ride Amazon's rails to reach market are increasingly dependent on their biggest competitor."

\section{NYT Sep 72018}

In thinking about the difficulty government advocates in the USA have in taming or tempering Amazon I turn to some literature on eccentric millionaires and power in the United States, Ronan Farrow's Catch or Kill as a starter. In the Epstein case Geoffrey Epstein operated from an island in the Caribbean flying in and out of the USA with illicit cargo in an unregulated fashion. Money talks across the law in this situation. Epstein kept operations in New 
Mexico and in other parts of the USA while situated, for some of the time at least, in an offshore base.

Again we come, perhaps, to the question as to whether Amazon needs the United States as a base. Why not an island state as a centre for Amazon, why not, say, Nauru, a state where the natural resource might be running out and there is a need for an economic benefactor of some kind? This might take takes us into the waters of Development Studies, to the example, say, of United Fruit in Latin America but it might equally take the argument to a case for a small, well run place friendly to Amazon along the lines that the anti- trust legislation in the USA allowed a developmental space for Amazon.

Without over-using the idea of development what could Amazon offer such a small state?

Could Amazon and the King Movement meet up through a Maori speaking intermediary state like the Cook Islands?

Can the US state be subsumed by Amazon? Can Amazon be subsumed by the US state?

Is Amazon an incipient state within the US?

Moving to the side and away from Amazon we can see in the Epstein saga certain tendencies. The private island, the airport in the USA where records are not kept for the entry and exit of planes owned by rich people. Epstein's idea of populating the world with his offspring or whatever that was raises thoughts about dynasty and the retreat from democracy into a kin based operation.

And speaking about kin based operations in the American context we can see in the Trump dynasty the significance of kin in the modern Republican party. At the 2020 convention there was a Trump at every key point 
with Donald himself being on every night of the three day event.

Noting that Bezos is not the late Epstein and is not Trump and they all have distinct identities, one important point here, going back especially to Dumaine, is the intention to serve in the Amazon culture. This is not leadership by fiat, not leadership by committee or by kin, it is leadership by ascription of power to the client, the intention is to out-serve any competition. The economic history of Amazon with its apparent disdain for the profit line and the attention to market dominance through service needs to be treated by an economist, Dumaine having done an initial description of some note as has Khan from a legal point of view. The flywheel works essentially by faster, more reliable service getting better and providing better value for money, better algorithms, all the time. The way the flywheel works is part of its attraction to the public and why the level of interest as well as trust is high. We might call this an incipient market state except that Amazon offers a comfort zone of immediate service through Alexa and other things considered below as well as a place to buy and sell.

A market state? Like the mercantile states of old, like Venice in days of yore or like Hong Kong in the loose reach of Great Britain prior to the re-connection to China? Or like nothing so far seen before, like the situation described in Hart's The Warehouse, a law unto itself with its hubs comprising opportunities and borders.

Or we might call it an algorithmic state given the use of Artificial Intelligence, robotics and algorithms throughout Amazon's operations. Algorithms determine price, they determine competition, they determine borders in the sense of what players are to come to market and what are to be kept out as well as how well Amazon's own products might fare in the market all done in terms of speed and reliability of service. And algorithms determine comfort 
and trust as Alexa meets the needs of clients from the most basic to the most abstruse..

This seems more like leadership from below, from around than from above. And here might be the key difference, the way, say, that Bezos and Trump differ utterly in style and the new thing that Bezos or rather the algorithms used by him bring, of the people and for the people... all the time and faster than anyone else with as good or better product.

New forms of state emerge from or break out of older forms. What kind of a host state for the likes of Amazon is the USA, is it a centralized. Jacobin type of state or a loose, more freewheeling sort of an outfit? Do we have crazed contradictions here? Is Trump actually a Jacobinist, a centralist in the guise of Republican freedom for the individual and Bezos more of a fan for an open form of the state as long as it allows him to be more central in people's lives? Or was there just a faulty crust in the law of state allowing, as Lina Khan points out, Amazon to escape a forced break up because of its size and market dominance and so break out into a new form.

The Trump-Bezos rift which seems to entail Trump knocking Bezos where he can over, say, Bezos' ownership of The Washington Post and, critically, over contracts to offer cloud services to the Pentagon means, or could mean, that Amazon is now operating in a hostile environment in the USA, an environment that is potentially in the way of the capacity to serve the consumer. This, surely, if we were to follow Dumaine on 'the flywheel' and 'Bezonomics' would be enough for Bezos to look for Amazon Country, just as followers of the Maori King in the hostile environment for them of the nineteenth century in New Zealand were first banished into and then found strength inside the King Country, a pandemic raging amongst Maori then as it is in the USA 
now giving a sharp edge to the idea of a hostile environment.

This was not always the case. Lina Khan in her Yale Law Review article is suggesting, I think, that through the legislation regarding big entities and the influence of the Chicago School on it the USA has offered a benign environment for the growth of Amazon and not a hostile one at least pre-Trump. This could be said to be the first multiplier for Amazon, the inadvertent growth of an entity initially on the back of but ultimately, from Khan's perspective at least, at the expense of consumer satisfaction, of price. The implication, at least from Khan's writing is that if the flywheel knocks out competition for Amazon's own products then ultimately there will be a false market and an untidy relation between price and value.

Bezos lucked into the crazed contradictions of a nationstate, the USA that wanted best prices for the consumer regardless of the scale of the supplier. He maxed that scale in ways not envisaged and created a market beyond other markets that might compete. He took his algorithms to town and came to own the market square.

The second multiplier is the pandemic. Covid 19 has meant that the world starts and ends for many at home and service to the home is Amazon's brief at which it excels and in which it is trusted in an intimate way as part of the family. To consider Alexa I would point to a book called Living Dolls by Gaby Wood who details the history of elementary robotics in forms acceptable and endearable to humans. These range from Vaucanson's's shitting duck to modern Japanese robots. Alexa offers soft comfort, accuracy in our clumsiest moments and the voice of a doll living in extremely close proximity to us.

What now given these multipliers and what new multipliers might we see? 
In terms of fulfilment of satisfaction Amazon is first port of call for books, goods, services and conveniences of all kinds. And here we go back to immediacy, to wish fulfilment in the moment- Amazon is almost in the moment- same day, same moment delivery.

All this with the voice of Alexa, the robotic tool to hand, the extension...Alexa could be the next multiplier, the first of a robot family to be with the human family and to potentially become as essential as the bra or the car. Does Alexa open the door to a complementary robot world, complementary to our basic needs? And could this close, this visceral, this immediate voice response be the harbinger of an altogether different type of multiplier, one at least as powerful as the others? Would this go with the rating of ourselves by AI set out in Black Mirror 1 and discussed by Jean Tirole.

Regarding the literature that I have read on hubs, really just a skim over Berry et al. on airline hubs, I will not evaluate these papers except to note that there is a quality literature on hubs and to point to it, one of the Berry articles offering an excellent reading list.. The different use of hubs by tourists and business travellers may in some respects be interesting here and I leave that for a later discussion which might open up to a consideration of a typology of hubs and their uses.

In one of his articles Berry cites a number of works on entry. I want to take the idea of entry, without a strict application to Berry or his references and think about entry points to a border, to a port, to a market. Khan's work argues, I think, that the Amazon project sets up borders that restrict entry points to the Amazon hub. This is of, course, not the same as an airport hub as discussed by Berry et al. but perhaps not utterly dissimilar. In the case of airports these are tangible, found in the terrestrial world. Amazon is operating its market in cyberspace. 
Amazon offers several kinds of hub; information hubs through the cloud and entertainment hubs as well as distribution hubs. Below I talk about intensification and multiplication and I ask here whether the study of hubs is critical now especially to consider how Amazon controls as well as offers its hubs. Does Amazon use the same kind of criteria for inclusion and exclusion in its market? This question gets us into whether Amazon is a predator that welcomes stall holders into its market and then proceeds to copy and then exclude exclude them.

Whichever question that might be asked of hubs it seems appropriate to suggest that their use, put together with the selection procedures of algorithms could be another multiplier, perhaps even more potent than others.

Is there some kind on commonality of algorithm across the various hubs?

Does Khan's work have implications beyond US law? Has Amazon used the US state and explored the contradiction in antitrust legislation there to set up a market now global in nature with its own entry points, its own customs, its own algorithmic culture?

We might turn again to notions of scale and refer back to West and his book on the subject. This market is not the village fete and the algorithms that control it are not like the Town Crier or the Mayor. The Amazon market is of such a scale that we might think of Amazon in terms of the ancient city states except that Amazon is not a city. It is a hub or set of hubs radically unlike but finding, perhaps, its antecedents in Venice in its day, London as a financial centre prior to exit from the EU or New York in its heyday, only bigger.

Amazon is a Silk Road in the sky going to places that Marco Polo never explored. 
The Washington Post is a kind of information hub and the ownership of it by Bezos might set him in something like the frame described by Hart in The Warehouse. Hart talks about the Bezos figure becoming the President in the context of information control both to the public at large and to the inhabitants of the distribution hubs. But again, Bezos in in service, giving the client what he wants, information, let's call it news, faster and more effectively but there is no need, apparently, for him to offer himself as Messiah as someone to lead followers out of a promised land. Once the client is trapped in a certain service mode then another form of service is to be found- the flywheel changes gear.

In regard to hubbing in the nineteenth century in New Zealand for Maori, Kawhia, a coastal port on New Zealand's West Coast was a shipping hub. But the drawing of a confiscation line in the 1860s and the retreat of the King Movement south of Kawhia to the King Country meant that the King Movement really worked as a ritual and conceptual hub, as a belief system until the opening up of the King Country in the 1880s. The King Movement served its followers in terms of identity...it offered hubs of metaphor and hope.

A future discussion of the typology of hubs might explore how various kinds of hubs are related. Sometimes this is clear but in the case of Bezonomics the relationship between distribution hubs, information hubs and the use of algorithms across them seems cloudy as though Bezos is simply being opportunistic when it comes to food, say, or outer space- all beginning of course with the supply of books which is where it all started. Is there an ideology, a sense of identity in all this? Should there be? Need there be?

Another way to look at all this is to take the basic subject involved, the client or the citizen and ask whether they 
are being served. The ethic at Amazon, the concentration on the client that Dumaine notes is central to all that Bezos does and is similar, or at least comparable, to the attention given to the citizen in a well functioning state. This attention it might be argued, fulfils a basic need and Bezos has taken this need and amplified it to be visceral, immediate and wish fulfilling.

Dependence is another thing though...

\section{Concluding thoughts}

Amazon exists to satisfy as much as possible of the needs of the client, those needs and wants in their totality. Better than anyone else.

After Amazon what do people want and need? This goes with the question; how are we to describe Amazon, is it a tech company or a totalizing entity? Is Amazon simply best described as a market? If so is it of a scale and significance to compare it to a small or not-so-small state with ports of entry controlled at its borders? If it is more than a market what do its features have in common? Algorithms.

Amazon's scale is such that several of the assertions in Geoffrey West's book Scale need revision in my view and I would call for a comparison by economic historians of the East India Company and Britain, of the railroad cartels and the US government and Amazon and the US government, Amazon and the world. There may be a new kid in town though...

In regard to the question whether Amazon depends on the US government I would suggest that we are now past the potential blocker of the corporate break up notwithstanding Khan's objections referred to above. In regard to the question whether the US government depends on Amazon, yes it does in terms of the service 
now rendered to the US public and, perhaps, no, it does not if we look at the matter of taxes. An economist will no doubt figure out the answer to the latter question and I leave it hanging.

And there might need to be a good look at the word 'resilient'. What is Amazon resilient to? To government, to the market it controls, to the world it spans? To turn the question around, is Amazon resilient to its own algorithms? Or to other forms of AI? At what point does Amazon as a corporate with shareholders become an obstacle to the flywheel of better and faster service?

It might be worth seriously asking the question, is Amazon an incipient state, an example of early state formation? It might be too early to get a serious answer but it is suggested here that the idea of client service, customer service and service to the citizen are not a million miles away from one another. The service-to-diefor mentality so well described by Dumaine and others might well be the harbinger of a political form that we do not, as yet know much about.

Can we not speak of the client and the citizen in the same breath?

The question above might be augmented with the following questions; the first and possibly most important point regarding the state is immediate and visceral and to do with the question- to what authority do people first turn? With Alexa Amazon is the first port of call in the morning and late at night. And what do people trust Amazon to do? Has Amazon entered the family in a way that states hitherto have not? Is Amazon something that family members share and so adjacent to kin? Is the option to prefer, to 'Like', an advance on what the state, as we know it offers in terms of a vote? 
So much of the above seems to be about hubs. Might we see here the early state, the incipient state, the state that might happen as a fusion of hubs, of central points of kinship, economy and status. We might see such fusion as sovereignty. There is also the city, the city state as a hub of power and this is ingrained perhaps in our thinking. Early state situations such as the Inca may not have had the industrialised city as a hub. We may be talking about pre-city and post-city with Incan, Egyptian and other early states and Amazon.

We are not talking about Amazon being a hub of military power, not so far at least. However we are in the context of war supply with Amazon having provided cloud support to the Pentagon.

We have not, so far, talked much about the hub as ritual and entertainment centre.

In the Kingitanga there is the idea of being under the maru or umbrella or under the mana of the King Movement. To what extent does Amazon offer protection? To what extent does Amazon offer shelter and security?

Then there is the screen. The first port is the screen on the computer or the phone and then its on to ports at hubs to suit the consumer. Then there is the cloud, an external authority, unseen and unknown in its potency but trusted nonetheless.

Then there is the overall context not considered in this short paper; 5G, Yuah Wei, Alibaba, Huawei, China, Oracle, Apple, Gates... a brief consideration of the ChinaUSA divide over tech, over TikTok and the like might lead again to the thought that either place, either state, the USA or China offer impediments to client service so as to form a hostile environment for Amazon. 
In both cases Bezos and the Maori King are made strangers at home. In the nineteenth century this happens to Maori through disease and war and for followers of the King Movement the confiscations and the exile to the King Country that followed the war in the 1960s. In the case of Bezos he has become an enemy of Trump with attacks on Bezos' ownership of The Washington Post and the cutting of the Pentagon supply contract. Could alienation from the home state, the host state, as it were, become a multiplier as new grounds for growth are sought and found? The placement of hubs, in this sense, becomes critical.

Finally, more might have been done above regarding the sovereignty issue of 1905, railroads and all that mentioned by Khan and then by Streitfeld of the New York Times and also by Dumaine. Sir George Grey's question of the Maori King at the outset of the Land Wars in New Zealand, 'Are there two suns in the sky?' might apply... 


\section{Bibliography}

Berry Steven, Carnall, Michael and Spiller, Pablo T, Airline Hubs, Costs, Markups and the Implications of Customer Heterogeneity National Bureau of Economic Research May 1996

Berry, Steven T Estimation of a Model of Entry in the Airline Industry Econometrica, Vol. 60, No. 4. (Jul., 1992), pp. 889-917

Cleave Peter Pan tribal and state-like formations Journal of the Polynesian Society

1983

The Sovereignty Game Victoria University Press 1990

Dumaine, Brian Bezonomics How Amazon is changing our lives and what the world is learning from it, Simon and Schuster 2020

Farrow, Ronan Catch and Kill, Lies. spies and a conspiracy to protect predators Fleet 2019

Hart, Rob The Warehouse Bantam Press 2019

Khan, Lina M. Amazon's Antitrust Paradox The Yale Law Journal 2017: 710-805

Tirole

Jean

https://www.tsefr.eu/sites/default/files/TSE/images/conference/Digi tal_conf_2020/tirole_digital_dystopia_080120.pdf

West, Geoffrey Scale, The Universal laws of Life, Growth, and Death in Organisms, Cities and Companies, Penguin 2017

Wood, Gaby Living Dolls, A Magical History of the Quest for Mechanical Life Faber and Faber 2002

\section{Articles and Internet References}

New York Times Sep 72018 David Streitfeld Amazon's Antitrust Antagonist Has a Breakthrough Idea; with a single, scholarly article, Lina Khan 29, has reframed decades of monopoly law

Black Mirror Episode One Season Two Fifteen Million Merits 